\title{
Functional Hearing Loss
}

National Cancer Institute

\section{Source}

National Cancer Institute. Functional Hearing LoSs. NCI Thesaurus. Code C116365.

Hearing loss in the absence of auditory system pathology. 